much of the cost of traditional journals. Some people believe that electronic publishing will fundamentally change the way that science gets done and may even spell the end of scientific publishing in its current form (p 1387). ${ }^{8}$

We hope that the $B M f$ s presence on the internet might help to change the one-to-many relationship the journal has with its readers. The electronic medium allows for much greater interaction than the traditional format of the journal, and our home page makes it easy for readers to send their comments back to us. At present we have just dipped our toes in the water; future electronic developments will be closely informed by what our readers tell us they want and need.

For those who felt out of their depth on reading the title and subtitle of this editorial and now feel that they are drowning we will be offering a more detailed guide to the internet and the World Wide Web in future issues, which is likely to be followed by a regular column devoted to the topic. Visitors to this year's annual representative meeting of the BMA in Harrogate in July will be able to see our home page at first hand-and so, from this week, will anyone with access to the internet, from Addis Ababa to Zagreb.

\section{TONY DELAMOTHE}

Deputy editor

$B M Y$,

London WC1H 9JR

bmj@bmj.com

1 Bartrip PWJ. Mirror of medicine. A history of the BMY. Oxford: Oxford University Press, 1990.

2 La Porte RE, Akazawa S, Hellmonds P, Boostrom E, Gamboa C, Gooch T, et al. Global public health and the information superhighway. $B M F$ 1994;308:1651-2.

3 Coiera E. Medical informatics. BM于 1995;310:1381-7.

4 Neubarth M. Web fever: catch it. Intermet World 1995 Apr:4.

5 Groves T. Information sharing: getting journals and books to developing countries. BMf 1993;307:1614-7.

6 Kale R. Health information for the developing world. $B M F$ 1994;309:939-42.

7 Schatz BR, Hardin JB. NCSA Mosaic and the world wide web: global hypermedia protocols for the internet. Science 1994;265:895-901.

8 La Porte RE, Marler E, Akazawa S, Sauer F, Gamboa C, Shenton C, et al. The death of biomedical journals. $B M \Im$ 1995;310:1387-90.

\title{
Ebola virus
}

\section{Poor countries may lack the resources to prevent or minimise transmission}

Twenty years ago Ebola virus first emerged in simultaneous outbreaks in Sudan ${ }^{1}$ and Zaire. ${ }^{2}$ Two subsequent outbreaks have occurred, ${ }^{34}$ but transmission among human populations has not been sustained. Despite substantial progress in our understanding of Ebola we have not identified its natural reservoir or the trigger for its re-emergence in new outbreaks in humans.

As the journal went to press, the World Health Organisation had reported 114 cases of Ebola infection and 79 deaths in a new outbreak centred in Kikwit, a rural town of 400000 situated in Bandundu Province, Zaire, $1000 \mathrm{~km}$ from the location of the 1976 outbreak in Zaire. ${ }^{5} \mathrm{~A}$ cordon sanitaire has been placed around the town, but some travellers have circumvented it. The few cases reported in nearby towns have so far been among already ill patients transferred from Kikwit to other hospitals. The index case, seen in early April, was a hospital laboratory worker presumed at first to have typhoid; subsequent cases were initially found among a surgical team and others who cared for the laboratory worker, with secondary spread to other health workers and to family members acting as carers. Two thirds of the deaths have been among health workers. Until the outbreak provoked a response, Kikwit General Hospital was short of barrier nursing supplies and disinfectants.

The current outbreak resembles earlier African outbreaks, ${ }^{1-3}$ in which the first cases were found in hospitals where infection control mechanisms were not in place because of economic constraints. Ebola virus was spread to health workers in contact with body fluids, and also from patient to patient by the reuse of unsterilised needles. Secondary transmission occurred also among family members who administered care, among those who prepared corpses for burial, and in other towns where travellers from the epicentre subsequently became ill and infected new carers. Airborne spread is not considered important; one study noted that those exposed to ill patients even in small, crowded village huts were not at increased risk without direct contact. ${ }^{3}$

Illness occurs 2-21 days after infection but generally within 7-14 days, beginning abruptly with headache, malaise, and fever; vomiting, bloody diarrhoea, or a maculopapular rash may develop a few days later. Severe bleeding and shock may follow and are likely to lead to death. No treatment exists beyond supportive care. Mortality reportedly ranges from $50 \%$ to $90 \% .^{1-3}$ Two thirds of cases have resulted in death in the current outbreak, but experience with more extensively studied viral haemorrhagic fevers suggests that very mild cases may go unrecognised. Early cases may also be difficult to differentiate from typhoid or malaria, and not even the late signs are specific; the identification of presumptive cases may be more difficult at present because of an unconfirmed outbreak of shigella dysentery.

Ebola and Marburg are members of a unique ribonucleic acid virus family, the filoviridae. ${ }^{6}$ Ebola virus nuclear protein and polymerase genes are distantly related to the equivalent paramyxovirus genes. ${ }^{7}$ The reason for the extreme pathogenicity of these agents is not understood. Virulence varies among strains ${ }^{8}$; sequencing of the current strain in Zaire by the United States Centers for Disease Control and Prevention shows that it resembles the one that caused the outbreak in 1976. ${ }^{9}$

Past outbreaks have been contained by identifying cases and introducing simple measures to prevent direct contact with body fluids and to limit travel. Experience indicates that nursing supplies, disinfectants, case identification measures, and the isolation and supportive care of ill patients are likely to be best provided where the outbreak is based, once national and international responses are in place. Public health officials must not only effect these measures but convince local people that they minimise risk not only to other communities but to themselves by staying put. Reassuring the public that people who have not been ill cannot transmit Ebola, even if they are infected, is difficult but crucial.

Specific guidance to consultants in communicable disease control, public health doctors, and port medical officers have been issued swiftly here and in similar countries unlikely to be affected by the outbreak. The response has been low key, with no quarantine placed on travellers from Zaire who are not ill and therefore not infectious. ${ }^{10}$ Timely communications and a coordinated response from clinicians, public health specialists, and virologists seem to have minimised media overreaction and public concern.

Local, national, and international responses in Zaire, involving a much greater need for resources, have also been put into place. Zaire is fortunate to have its own epidemiologist 
with experience in the previous outbreak to coordinate these responses. Within days, surveillance systems were operating and early exaggerated reports were contradicted. International teams soon arrived to provide additional epidemiological and clinical support. Bodies are now being picked up and disposed of by the Red Cross, and the community has been educated about the simple measures necessary to minimise risk. Active case finding is taking place at health centres within Kikwit and at remote sites within a radius of $150-200 \mathrm{~km}$; cases and deaths are being systematically identified and contacts exhaustively traced. Gowns, gloves, and masks have been flown in; nurses from peripheral health posts are receiving training. Kikwit's hospital now has access to drinking water and a few hours of electricity daily; surfaces are regularly disinfected. Despite all this, the number of cases will inevitably rise in the next three weeks among those already infected.

The experience so far underlines the importance of disease surveillance for an early response and provokes a commitment to support the intensive efforts until the outbreak is contained. But the outbreak also highlights the difficulties poorer countries have in sustaining the simple measures that could have prevented or minimised not only Ebola transmission but other more ordinary but no less dangerous nosocomial risks. Deaths from an exotic, incompletely characterised virus should not be necessary to remind us of the need for barrier nursing supplies and routine precautions when there is exposure to body fluids. The present opportunity for rich countries to bring the weight of modern molecular virology to bear on Ebola virus should not deflect from the greater priority to strengthen training of health care staff and improve facilities in poorer countries.

DIANE BENNETT

Communicable Disease Surveillance Centre,

Public Health Laboratory Service,

London NW9 5EQ

Consultant epidemiologist

DAVID BROWN Director

Enteric and Respiratory Virus Laboratory,

Public Health Laboratory Service

\footnotetext{
1 Report of an International Commission. Ebola haemorrhagic fever in Sudan, 1976. Bull World Health Organ 1978;56:247-70.

2 Report of a WHO/International Study Team. Ebola haemorrhagic fever in Zaire, 1976. Bull World Health Organ 1978;56:271-93.

3 Baron RC, McCormick JB, Zubeir OA. Ebola virus disease in southern Sudan: hospital dissemination and intrafamilal spread. Bull World Health Organ 1983;61:997-1003.

4 Jahrling DB, Geisbert TW, Dalgard DW, Johnson ED, Ksiazek TG, Hall WC, et al. Preliminary report: isolation of Ebola virus from monkeys imported to USA. Lancet 1990;335:502-5. report: isolation of Ebola virus from monkeys imported to
Ebola haemorrhagic fever. Wkly Epidemiol Rec 1995;70:147.

5 Ebola haemorrhagic fever. Wkly Epidemiol Rec 1995;70:147. Kiley MP, Bowen ETW, Eddy GA, Isaacson M, Johnson KM, McCormick JB,
taxonomic home for Marburg and Ebola viruses? Intervirology 1982;18:24-32.

Feldmann H, Klenk HD, Sanchez A. Molecular biology and evolution of filoviruses. Arch Virol 1993;7:81-100.

8 Fisher-Hoch SP, Brammer TL, Trappier SG, Hutwagner LC, Farrar BB, Ruo SL, et al. Pathogenic potential of filoviruses: role of geographic origin of primate host and virus strain. $\mathcal{F}$ Infect Dis 1992;166:753-63.

9 Department of Health and Social Security and the Welsh Office. Memorandum on the control of viral haemorrhagic fevers. London HMSO, 1986.

10 Outbreak of Ebola viral hemorrhagic fever-Zaire 1995. MMWR Morb Mortal Wkly Rep 1995; 44:381.
}

\section{Spinal cord injuries in rugby union players}

\section{How much longer must we wait for proper epidemiological studies?}

Recognition nearly 20 years ago of a high incidence of spinal cord injuries in rugby union players ${ }^{1}$ led eventually to changes in the rules in most rugby playing countries. New Zealand changed its rules in 1980 and 1984; Britain in 1979, 1984, and 1985; Australia in 1985; and South Africa in 1990. The consensus is that these changes have produced the desired effect, but how robust is the evidence? The week in which the Rugby World Cup begins in South Africa seems an apt time to address this question.

Silver's study of 63 spinal cord injuries in rugby union players between 1952 and 1982 was important in identifying mechanisms of injury in a representative sample of rugby players. ${ }^{2}$ But it was not a study of incidence. Two further studies by him included all spinal cord injuries in rugby players treated in eight spinal units in England and Wales between 1980 and $1986 .{ }^{34}$ By this time the incidence of spinal cord injuries should have begun to fall if the actions taken by the English Rugby Football Union had been effective.

These data show that, although the annual incidence of spinal cord injuries at Stoke Mandeville Hospital fell steadily from a peak of nine admissions in the 1980-1 season to two in 1986-7, the overall incidence of reported spinal cord injuries in rugby union players in England and Wales remained fairly constant between 1980 and 1986. Clearly these data do not support Silver's conclusion that a fall in the incidence of serious injury in Britain has followed changes in the laws of rugby. ${ }^{5}$ Until complete data from all spinal units in Britain have been analysed (the numerator) and the total number of rugby players in Britain is known (the denominator), no conclusions regarding the effects of recent rule changes can be drawn.

Similar uncertainty exists in other rugby playing countries. Burry and Calcinai reported that the average annual incidence of spinal cord injuries in New Zealand fell from nine between 1973 and 1978 to less than three in $1985-6$ as a result of specific rule changes that reduced the number of injuries in scrums and loose rucks or mauls. ${ }^{6}$ Calcinai's more recent data show that the number of spinal cord injuries in New Zealand rugby players rose again in the 1988 and 1989 rugby seasons: incidence in 1989 was not lower than that before the rules were first changed in $1980 .^{7}$ (Only three further injuries were reported in the 1990 and 1991 seasons so the average annual incidence between 1988 and 1991 fell back to four.)

But the accuracy of these data must now be questioned in the light of Dixon's analysis of hospital discharges for rugby injuries, including spinal cord injuries, in New Zealand rugby players between 1980 and $1990 .{ }^{8}$ If we assume that Dixon's methods were correct Calcinai and Burry apparently identified only about half of all spinal cord injuries in New Zealand rugby players.

Interestingly, Dixon showed that spinal cord injuries peaked in 1984 and 1986 - after the introduction of what were considered to be effective rule changes. It is therefore premature to conclude that the incidence of spinal cord injuries related to rugby has fallen in New Zealand.

The sole data for spinal cord injuries in South African rugby players come from a 30 year survey of admissions to the spinal unit at the Conradie Hospital in Cape Town, the source of the original study of spinal cord injuries in rugby players. ${ }^{19}$ The most recent analysis of those data shows that admissions of rugby union players with spinal cord injuries rose progressively during the $1980 \mathrm{~s}$ with a peak incidence of 12 admissions in $1989 .{ }^{10}$

In the past four seasons (1990-93), there have been a further 31 spinal cord injuries in rugby players. This is fewer than the 